\title{
Designing Cropping Systems to Improve the Management of the Invasive Weed Phalaris minor Retz.
}

\author{
Gaofeng Xu ${ }^{1,2}{ }^{1}$, Shicai Shen ${ }^{2}$, Yun Zhang ${ }^{3}$, David Roy Clements ${ }^{4}{ }^{\oplus}$, Shaosong Yang ${ }^{2}$, Jun Li ${ }^{1}$, \\ Liyao Dong ${ }^{1, *}$, Fudou Zhang ${ }^{2, *}$, Guimei Jin ${ }^{2}$ and Yuan Gao ${ }^{1}$ \\ 1 College of Plant Protection, Nanjing Agricultural University, Nanjing 210095, China; \\ xugaofeng1059@163.com (G.X.); li_jun@njau.edu.cn (J.L.); yuangao@njau.edu.cn (Y.G.) \\ 2 Institute of Agricultural Environment and Resources Research, Yunnan Academy of Agricultural Sciences, \\ Kunming 650205, China; sshicai@csu.edu.au (S.S.); yshaos@163.com (S.Y.); yfjgm2019@163.com (G.J.) \\ 3 Biotechnology and Germplasm Resources Institute, Yunnan Academy of Agricultural Sciences, \\ Kunming 650205, China; zhangyun507@163.com \\ 4 Biology Department, Trinity Western University, 7600 Glover Road, Langley, BC V2Y 1Y1, Canada; \\ clements@twu.ca \\ * Correspondence: dly@njau.edu.cn (L.D.); fdzh@vip.sina.com (F.Z.); Tel.: +86-256-692-8708 (L.D.); \\ +86-871-6589-4429 (F.Z.)
}

Received: 20 October 2019; Accepted: 25 November 2019; Published: 27 November 2019

\begin{abstract}
Because cropping systems can greatly affect the establishment and spread of alien species populations, the design of cropping systems to control invasive weeds is an important approach for invasive species management in agro-ecosystems to avoid excessive increases in other control measures such as herbicides. The annual weed Phalaris minor Retz. (P. minor) is one of the most troublesome invasive weed species of winter crops in Yunnan Province, China, but the development of cropping systems for ecological control of this weed have received limited research attention. Here, we studied seed dormancy, germination characteristics and reproductive responses of $P$. minor to various cropping systems to show how cropping systems could be better designed to control P. minor in China. Our research showed that cropping systems significantly affected seed dormancy in submerged paddy fields. Phalaris minor seed remained dormant and the germination rates (less than $10 \%)$ were significantly lower $(p<0.05)$ than in maize fields and dry, bare soil conditions. Wheat, faba bean and rapeseed crops had no significant influence $(p<0.05)$ on the seed germination rate of P. minor, but increasing soil depth significantly decreased $(p<0.05)$ the germination rate and germination index of this weed. Total biomass, spike biomass, spike number and seed number of P. minor were significantly reduced $(p<0.05)$ with increasing proportions of the three crops (wheat, faba bean and rapeseed), with rapeseed having the strongest inhibition effects among the three crops. The reproductive allocation and reproductive investment of $P$. minor were also significantly reduced $(p<0.05)$ in mixed culture with wheat and rapeseed. With increasing proportions of wheat or rapeseed, the specific leaf area of $P$. minor significantly increased $(p<0.05)$, but the reverse was true for leaf area and specific leaf weight. Moreover, the net photosynthetic rate, stomatal conductance and transpiration rate for P. minor also decreased significantly $(p<0.05)$ when grown with wheat or rapeseed. These results suggest that optimal cropping systems design could involve planting rapeseed in conjunction with deep plowing and planting rice (continuous submergence underwater) in summer. Such a system could reduce the field populations and seed bank of P. minor, thus providing a sustainable and environmentally friendly means of suppressing $P$. minor.
\end{abstract}

Keywords: Phalaris minor; cropping systems; ecological control; seed dormancy; seed germination; reproductive characteristics 


\section{Introduction}

Phalaris minor Retz. (P. minor), littleseed canarygrass (Poaceae), is an annual weed native to the Mediterranean region [1,2]. Currently, it has been reported in more than 60 countries and is widely distributed in every continent except for the polar regions [2,3]. The invasive weed, P. minor, was considered to be the predominant and most troublesome annual grass weeds in agro-ecosystems in many regions, and has resulted in serious yield reductions of most agronomic crops, particularly wheat $[4,5]$. At present, use of chemical herbicides (e.g., isoproturon, fenoxaprop-P-ethyl and pinoxaden) is the main method used for control of this weed $[2,6,7]$. However, long-term usage of chemical herbicides has created environmental pollution, herbicide resistance and human health problems [8]. Moreover, use of chemical herbicides and/or manual removal are difficult and have low efficiency for controlling P. minor at the wheat seedling stage because the two species have similar morphology, physiology and phenophases $[2,9,10]$. Utilizing crop allelopathy to inhibit this weed is one of the more environmentally friendly approaches tested, but few have succeeded [11,12]. Controlling this weed using ecologically sustainable approaches is still a worldwide challenge.

The successful establishment of non-native species is closely related to the invaded habitats $[13,14]$. For agro-ecosystems, modifying cropping systems could affect the occurrence and damage caused by invasive species, potentially affecting their control strategies and control efficiency $[15,16]$. Therefore, it is essential to determine the spatial-temporal population dynamics of $P$. minor in different cropping systems, which is also an important prerequisite for controlling this weed. As an annual herbaceous invader, the seed and seedling characteristics of $P$. minor play an important role in successful establishment, and therefore modification of cropping systems could affect seed dormancy, germination and reproduction. Thus, studies of the bio-ecological characteristics of seed dormancy, germination characteristics and reproductive responses to various cropping systems are critical for future ecological control of P. minor.

Previously, information on seed dormancy, germination and reproductive characteristics of $P$. minor showed that after dispersal P. minor seeds underwent true dormancy for 3-6 months and seed dormancy could be regulated by environmental factors $[17,18]$. For example, the germination of $P$. minor seed was higher when the seed was exposed to white light after dispersal compared to germination in the dark (wrapped in aluminum foil) [18]. Moreover, studies demonstrated that this weed generally produced 10-50 spikes per plant and generated a large number of seeds in wheat fields. Some studies have also shown that wheat varieties and planting density affected $P$. minor seed production $[19,20]$.

Phalaris minor became established in China in the 20th century and is presently among the most destructive invasive weeds in temperate and subtropical regions of Yunnan Province, China [21,22]. In these regions, wheat, faba bean and rapeseed are the main winter crops, and rice and maize are the main summer crops. In a previous study, we investigated the population characteristics of $P$. minor in different crop types and found the population density of P. minor in the field with long-term planting of rapeseed were significantly lower than when planting wheat or faba bean [22]. In subsequent studies, the measurement of the total biomass and tiller number of $P$. minor indicated that rapeseed was more competitive than wheat and faba bean in suppressing P. minor [23]. However, there was still limited information available on how particular crops and cropping systems might influence the occurrence and damage of P. minor.

In our previous studies, the population characteristics of this weed were reported for different crop types. However, the biological and ecological characteristics of various cropping systems are not well characterized. For the present study, we set up greenhouse and field experiments to investigate seed dormancy, germination characteristics and reproductive response of $P$. minor to various crop types and tillage methods. Specifically, our objective was to test the hypothesis that cropping systems could be designed to improve the control of the invasive weed P. minor in agro-ecosystems. 


\section{Materials and Methods}

\subsection{Study Site}

Field experiments were conducted at Songming Experimental Base of Yunnan Academy of Agricultural Sciences, Kunming city $\left(25^{\circ} 12^{\prime}-25^{\circ} 39^{\prime} \mathrm{N}, 102^{\circ} 76^{\prime}-102^{\circ} 89^{\prime} \mathrm{E}\right)$. This area is characterized by a typical north-temperate climate, rainfall averages $1035 \mathrm{~mm}$ per year and the annual mean temperature is $15{ }^{\circ} \mathrm{C}$ [24]. The experiment site is in a rice-wheat rotation and no herbicide was used in the previous crop. The soil properties were: $\mathrm{pH} 6.2$, organic content $18.14 \pm 0.17 \mathrm{~g} / \mathrm{kg}$, total N $1.63 \pm 0.12 \mathrm{~g} / \mathrm{kg}$, total P $0.37 \pm 0.08 \mathrm{~g} / \mathrm{kg}$, and total K $8.41 \pm 0.17 \mathrm{~g} / \mathrm{kg}$. Although P. minor is now widely distributed in farmland of Kunming City, there was no P. minor observed at the experimental site over the past 2 years.

\subsection{Study Species}

Phalaris minor is one of the most serious invasive species in winter crops, causing yield losses in wheat and other winter crops, as seen in the Kunming area, where this study took place [5]. Seeds of P. minor were collected from wheat fields near the field test sites on 15 April 2017. The average weight of 1000 seeds was $1.49 \pm 0.05 \mathrm{~g}$ and the germination rate was $91.8 \%$, as tested prior to experimentation.

Rice, maize, wheat, faba bean and rapeseed are the main summer and winter crops in Yunnan Province. Rice variety (cv. Yunjing No. 36), maize variety (cv. Yunrui No. 88), wheat variety (cv. Yunxuan No. 2), broad bean variety (cv. Fengdou No. 6) and rapeseed (cv. Yunyou No. 2) were obtained from the Rice Research Institute, Yunnan Academy of Agricultural Sciences (YAAS) for use in the experiments.

\subsection{Influence of Cropping Systems on Seed Dormancy of P. minor}

To understand the effect of cropping systems on seed dormancy of $P$. minor, a simulation test in the greenhouse was performed in 2017 from April to August, where average temperatures were between $20^{\circ} \mathrm{C}$ and $35^{\circ} \mathrm{C}$. The experiment consisted of three treatments: (A) Seeds buried in dry soil (never watered and no plants present); (B) seeds buried in a maize field (watered once every 5 days); (C) seeds buried in a rice field (kept continuously submerged in water). Each treatment was replicated four times in a randomized block design. All of the plots were placed in separate cement pools $(1.5 \times 1.5 \mathrm{~m})$, for a total of 12 cement pools. We selected 200 seeds with uniform size and color, put them into a nylon fabric attached to a long rope. We buried 4 nylon fabric bags randomly within of each plot at $12 \mathrm{~cm}$ depth, and kept the long rope on the surface. Then, we planted rice and maize in the corresponding plots at a constant planting density of 36 plants $\mathrm{m}^{-2}(0.20 \times 0.20 \mathrm{~m}$ spacing $)$ on 10 April. During the experiment, no fertilizers or pesticides were used and the weeds within the rice and maize plots were removed manually except for $P$. minor. Every month (up to 5 months), we randomly took out a seed bag from each plot, collected 100 seeds and cleaned. Seeds were separated from the medium and sown in Petri dishes (four replicates) on different dates and kept at $20^{\circ} \mathrm{C}$ in an incubator. During the experiment, seedling emergence was recorded every day. A seed was coded as "germinated" if the new shoots exceeded $1 \mathrm{~cm}$ in length.

\subsection{Influence of Cropping Systems on Seed Germination of P. minor}

To understand the effect of the cropping system on seed germination of this weed, we tested the seed germination rate of rhizosphere soil for different crops at different depths on 25 September 2017. We planted wheat, faba bean and rapeseed in plastic nursery seedling trays $(54 \times 28 \mathrm{~cm})$, which had 50 holes, in the greenhouse on 8 October 2017. After seeding, we moved the plastic nursery seedling trays to cement pools with a water depth of 1-2 $\mathrm{mm}$ and maintained one plant in each hole by thinning. Rhizosphere soil samples for wheat, faba bean and rapeseed were collected 30 days after sowing. Soil without planted crops was treated as the control.

A potted plant experiment was carried out to investigate the effects of different crops and soil depths on seed germination of $P$. minor. The experiment consisted of four different soils, including wheat rhizosphere soil, faba bean rhizosphere soil, rapeseed rhizosphere soil and control soil, combined with 
five treatments of burial depth, including $0,3,6,9$ and $12 \mathrm{~cm}$. Plastic containers $(50 \times 20 \times 16 \mathrm{~cm}$ deep $)$ were filled with $14 \mathrm{~cm}$ deep rhizosphere soil of wheat, faba bean, rapeseed and control soil, respectively. Each container was further divided into five equal boxes $(10 \times 20 \times 16 \mathrm{~cm}$ deep) with each randomly assigned to 1 of 5 burial depth treatments, and in each box, 5 gaps with the same depth were extruded with plastic cards, and 30 seeds were sown in each gap in evenly spaced positions, which was then covered with corresponding rhizosphere soil. For the seeds buried at $0 \mathrm{~cm}$, seeds were placed on the surface of the soil and gently pressed to the soil by hand. Tap water was supplied daily to keep the soil moist.

During the experiment, seedling emergence was recorded daily. A seed was coded as "germinated" if the new shoots exceeded $1 \mathrm{~cm}$ in length. The experiment was terminated 30 days after sowing.

\subsection{Influence of Cropping Systems on Reproductive Characteristics of P. minor}

To test how different crops would impact the reproductive [25] and physiological characteristics [26] of this weed, we carried out a field experiment at the experimental farm at Yunnan Academy of Agricultural Sciences in Kunming City, China, from October 2017 to May 2018. Treatments comprised the three test crops (wheat, faba bean and rapeseed) and the weed (P. minor) in pure and mixed cultures (four proportions), utilizing a de Wit replacement series method [27].

The seeds of wheat, faba bean, rapeseed and P. minor were planted in plastic nursery seedling trays $(54 \times 28 \times 5 \mathrm{~cm}$ ), which had 50 holes in the greenhouse on 8 October 2017. After 30 days, similar-sized seedlings of the four plant species were transplanted. Four ratios of crops and P. minor plants were established (2:1, 1:1, 1:2, 0:3) while maintaining a constant planting density of 36 plants $\mathrm{m}^{-2}$ $(0.20 \times 0.20 \mathrm{~m}$ spacing $)$. All plots were arranged in a complete randomized design with 4 replicates in $4 \mathrm{~m}^{2}$ plots $(2 \times 2 \mathrm{~m})$. All crops and P. minor plants were distributed evenly within the plot. During the experiment, the weeds within the plot were removed manually, except for $P$. minor. The experimental plots were fertilized with $750 \mathrm{~kg} \mathrm{ha}^{-1}$ calcium superphosphate and $150 \mathrm{~kg} \mathrm{ha}^{-1}$ urea before planting and $75 \mathrm{~kg} \mathrm{ha}^{-1}$ urea at 60 days after transplanting. During peak flowering times, twenty main spikes of $P$. minor in each plot were randomly sampled and wrapped using net bags. After 120 days of transplantation, the number and dry weight of $P$. minor seeds were measured.

We harvested the plants at $120 \mathrm{~d}$ following transplantation. Twenty P. minor plants were selected randomly and harvested within the middle region of each plot. First, we counted the number of spikes, 40 fully expanded leaves (flag leaf and the top second leaf) were selected, and leaf area (LA) was determined using a portable laser leaf area instrument (CID-203, Li-Cor) [26]. The shoots, spikes and roots of twenty P. minor plants were sampled and placed in separate paper bags. Harvested plant parts were oven-dried at $80{ }^{\circ} \mathrm{C}$ for $48 \mathrm{~h}$ and then weighed. Specific leaf area (SLA) $\left(\mathrm{cm}^{2} \mathrm{~g}^{-1}\right)$ was calculated as area per unit dry mass. The ratio of leaf biomass to total biomass yielded the leaf weight ratio (LWR). Leaf area ratio (LAR) was calculated as the ratio of leaf area to plant weight.

During peak flowering times, fully expanded sun leaves (flag leaf and the top second leaf) of each species were selected for gas exchange measurements [27]. At the same time, chlorophyll fluorescence and gas exchange parameters were determined using the Li-6400XT portable gas exchange system (LI-COR Inc., Lincoln, NB, USA). Photosynthetic active radiation (PAR) was obtained by using a quartz halogen light unit coupled to a leaf chamber. During measurements, the relative air humidity $60 \%-70 \%$, leaf temperature $25 \pm 1{ }^{\circ} \mathrm{C}$, and vapor pressure deficit (VPD) $2.0 \pm 0.5 \mathrm{k} \mathrm{Pa}$. Net photosynthetic rate $(\mathrm{Pn})$, intercellular $\mathrm{CO}_{2}$ concentration $(\mathrm{Ci})$, stomatal conductance $(\mathrm{Gs})$, transpiration rate $(\mathrm{Tr})$ and water use efficiency (WUE) were determined [28,29].

\subsection{Statistical Analysis}

The germination data were recorded until the 15th day, we calculated the germination ratio and germination index of P. minor using the following parameters [22]:

(1) Germination rate $(\%)=($ Total number of germinated seeds/total seed number $) \times 100$.

(2) Germination index $(G I)=\Sigma \mathrm{Gt} / \mathrm{Dt}$ (Gt is the germination number at the $t$ day, $\mathrm{Dt}$ is the corresponding number of germination days). 
Reproductive characteristics of P. minor were calculated using the following parameters [25]:

(1) Reproductive allocation $\left(\mathrm{g} \cdot \mathrm{g}^{-1}\right)=$ spike biomass/total biomass of each plant.

(2) Reproductive investment $\left(\mathrm{g} \cdot \mathrm{g}^{-1}\right)=$ seed biomass/total biomass of each plant.

(3) Reproductive index $\left(\mathrm{g} \cdot \mathrm{g}^{-1}\right)=$ seed biomass/spike biomass of each plant.

All growth variables (seed germination number, germination index, leaf area, spike number, seed number spike biomass, seed biomass and total biomass) and physiological variables (Pn, Gs, Ci, Tr and WUE) of P. minor were analyzed by analysis of variance (One-way ANOVA) using the SPSS 23.0 software package (SPSS, Inc., Chicago, IL, USA). I Data were checked for homogeneity of Variance. Treatment means were separated with Tukey's HSD and Post Hoc Multiple Comparisons, at the 0.05 significance level.

\section{Results}

\subsection{Seed Dormancy Characteristics of P. minor under Different Crop Types and Tillage Methods}

The results showed that the seed germination rates of $P$. minor varied significantly under different crop types (Table 1). After 30 days of seed dispersal, the germination rates (less than $10 \%$ ) of P. minor in the rice field were significantly lower than in the maize field and dry, bare soil conditions. Under the maize field and dry, bare soil conditions, the germination rates of $P$. minor increased significantly $(p<0.05)$ every month from seed dispersal to 120th day, over the length of the treatment, however, in the rice field (seed kept continuous submerged in water), the germination rates were less than $10 \%$ and leveled off rapidly over the season.

Table 1. Effects of summer crops on seed dormancy of P. minor.

\begin{tabular}{ccccccc}
\hline \multirow{2}{*}{ Treatment } & \multicolumn{7}{c}{ Germination Rate under Different Buried Period (\%) } \\
\cline { 2 - 7 } & $\mathbf{0 ~ d}$ & $\mathbf{3 0 ~ d}$ & $\mathbf{6 0 ~ d}$ & $\mathbf{9 0 ~ d}$ & $\mathbf{1 2 0 ~ d}$ & $\mathbf{1 5 0 ~ d}$ \\
\hline $\mathrm{A}$ & $2.7 \pm 0.3 \mathrm{e}$ & $20.0 \pm 1.2 \mathrm{~d}$ & $60.3 \pm 2.2 \mathrm{c}$ & $65.9 \pm 2.4 \mathrm{~b}$ & $71.1 \pm 2.8 \mathrm{a}$ & $74.4 \pm 2.4 \mathrm{a}$ \\
$\mathrm{B}$ & $2.7 \pm 0.3 \mathrm{e}$ & $11.9 \pm 0.9 \mathrm{~d}$ & $35.1 \pm 1.4 \mathrm{c}$ & $73.3 \pm 2.6 \mathrm{~b}$ & $81.9 \pm 2.2 \mathrm{a}$ & $75.3 \pm 2.6 \mathrm{a}$ \\
$\mathrm{C}$ & $2.7 \pm 0.3 \mathrm{a}$ & $2.7 \pm 0.3 \mathrm{a}$ & $4.3 \pm 0.4 \mathrm{a}$ & $4.7 \pm 0.2 \mathrm{a}$ & $5.1 \pm 0.2 \mathrm{a}$ & $5.1 \pm 0.3 \mathrm{a}$ \\
\hline
\end{tabular}

Data are expressed as mean \pm standard error. The different letters within the same row mean significant differences at $p<0.05$. (A) Seed buried in dry soil (never watered); (B) Seeds buried in the maize field (watered once every 5 days); (C) Seeds buried in rice field (continuously submerged in water).

\subsection{Seed Germination Characteristics of P. minor under Different Crop Types and Tillage Methods}

Crops of wheat, faba bean and rapeseed had no influence on the germination rate of $P$. minor seed, but significantly influenced $(p<0.05)$ its germination index, which was lowest in rapeseed treatment for the three upper burial depths (Table 2). The germination rate and germination index of P. minor seed were significantly affected by burial depth. Increasing soil depth significantly decreased the germination rate and germination index of this weed, but a few seeds germinated even at a burial depth of $12 \mathrm{~cm}$. 
Table 2. Effects of crops and burial depth on germination rate and germination index of $P$. minor.

\begin{tabular}{lcccccc}
\hline \multirow{2}{*}{ Items } & \multirow{5}{*}{ Accompanying Plant } & \multicolumn{5}{c}{ Burial Depth (cm) } \\
\cline { 3 - 7 } & & $\mathbf{0 . 0}$ & $\mathbf{3 . 0}$ & $\mathbf{6 . 0}$ & $\mathbf{9 . 0}$ & $\mathbf{1 2 . 0}$ \\
\hline \multirow{3}{*}{ Germination Rate (\%) } & Wheat & $96.0 \pm 0.7 \mathrm{a}$ & $82.0 \pm 2.4 \mathrm{~b}$ & $67.3 \pm 4.3 \mathrm{c}$ & $29.0 \pm 3.5 \mathrm{~d}$ & $4.5 \pm 1.6 \mathrm{e}$ \\
& Faba bean & $95.3 \pm 1.2 \mathrm{a}$ & $84.0 \pm 2.0 \mathrm{~b}$ & $67.0 \pm 4.4 \mathrm{c}$ & $30.0 \pm 2.8 \mathrm{~d}$ & $5.3 \pm 0.8 \mathrm{e}$ \\
& Rapeseed & $94.3 \pm 1.1 \mathrm{a}$ & $84.0 \pm 0.9 \mathrm{~b}$ & $60.3 \pm 3.5 \mathrm{c}$ & $31.0 \pm 2.4 \mathrm{~d}$ & $5.5 \pm 0.5 \mathrm{e}$ \\
& Control & $96.3 \pm 0.9 \mathrm{a}$ & $84.8 \pm 0.5 \mathrm{~b}$ & $69.5 \pm 1.6 \mathrm{c}$ & $31.35 \pm 1.2 \mathrm{~d}$ & $5.8 \pm 0.9 \mathrm{e}$ \\
\hline \multirow{3}{*}{ Germination Index } & Wheat & $19.1 \pm 0.2 \mathrm{a}$ & $11.6 \pm 0.5 \mathrm{~b}$ & $6.9 \pm 0.4 \mathrm{c}$ & $2.7 \pm 0.3 \mathrm{~d}$ & $0.3 \pm 0.1 \mathrm{e}$ \\
& Faba bean & $18.6 \pm 0.5 \mathrm{a}$ & $11.7 \pm 0.4 \mathrm{~b}$ & $6.8 \pm 0.4 \mathrm{c}$ & $2.8 \pm 0.3 \mathrm{~d}$ & $0.4 \pm 0.0 \mathrm{e}$ \\
& Rapeseed & $15.5 \pm 0.4 \mathrm{a}$ & $10.0 \pm 0.1 \mathrm{~b}$ & $5.8 \pm 0.4 \mathrm{c}$ & $2.7 \pm 0.3 \mathrm{~d}$ & $0.3 \pm 0.0 \mathrm{e}$ \\
& Control & $19.8 \pm 0.5 \mathrm{a}$ & $11.5 \pm 0.4 \mathrm{~b}$ & $7.3 \pm 0.1 \mathrm{c}$ & $3.0 \pm 0.1 \mathrm{~d}$ & $0.4 \pm 0.1 \mathrm{e}$ \\
\hline
\end{tabular}

Data are expressed as mean \pm standard error. The different letters within the same row mean significant differences at $p<0.05$. 


\subsection{Effects of Crop Types and Tillage Methods on Reproductive Characteristics of P. minor}

The growth and reproduction of P. minor varied greatly depending on crop environment (Table 3). In mixed culture, the total plant biomass, biomass and number of spike and seed number of $P$. minor were significantly $(p<0.05)$ suppressed with increasing proportions of wheat and rapeseed. However, faba bean was less suppressive than the other crops, with the spike and seed number of $P$. minor actually higher than in monoculture at ratios of faba bean to P. minor of 1:1 and 1:2.

Crop type and its relative abundance also elicited significant effects on reproductive allocation and reproductive investment of $P$. minor (Table 3). Under the same conditions, the reproductive allocation and reproductive investment of this weed were greatest when grown with faba bean and were the smallest when grown with rapeseed. With proportional increases in wheat and rapeseed, reproductive allocation and reproductive investment of $P$. minor became significantly lower $(p<0.05)$. However, in a mixed culture with faba bean, for the ratio of faba bean to $P$. minor of $1: 1$ and 1:2, the reproductive allocation exhibited no significant changes compared with the monoculture.

Table 3. Reproductive characteristics of $P$. minor growing as a monoculture and mixed culture conditions at different crop:weed ratios.

\begin{tabular}{|c|c|c|c|c|c|}
\hline \multirow{2}{*}{ Variables } & & \multicolumn{4}{|c|}{ Ratios (Crops: P. minor) } \\
\hline & & $2: 1$ & $1: 1$ & $1: 2$ & $0: 3$ \\
\hline \multirow{3}{*}{ Total biomass (g) } & Wheat & $4.7 \pm 0.1 \mathrm{~d}$ & $5.7 \pm 0.1 c$ & $6.1 \pm 0.1 b$ & $6.5 \pm 0.1 \mathrm{a}$ \\
\hline & Faba bean & $6.0 \pm 0.1 b$ & $6.9 \pm 0.2 \mathrm{a}$ & $6.8 \pm 0.1 \mathrm{a}$ & $6.5 \pm 0.1 \mathrm{a}$ \\
\hline & Rapeseed & $3.2 \pm 0.1 \mathrm{~d}$ & $4.0 \pm 0.1 c$ & $5.3 \pm 0.1 b$ & $6.5 \pm 0.1 \mathrm{a}$ \\
\hline \multirow{3}{*}{ Spike number } & Wheat & $6.9 \pm 0.2 c$ & $7.4 \pm 0.2 c$ & $9.8 \pm 0.3 b$ & $12.3 \pm 0.2 \mathrm{a}$ \\
\hline & Faba bean & $7.7 \pm 0.2 \mathrm{~d}$ & $10.6 \pm 0.3 b$ & $9.9 \pm 0.1 c$ & $12.3 \pm 0.2 \mathrm{a}$ \\
\hline & Rapeseed & $3.5 \pm 0.1 c$ & $4.0 \pm 0.1 c$ & $6.5 \pm 0.3 b$ & $12.3 \pm 0.2 \mathrm{a}$ \\
\hline \multirow{3}{*}{ Seed number } & Wheat & $547.8 \pm 31.0 \mathrm{~d}$ & $805.8 \pm 35.7 \mathrm{c}$ & $982.5 \pm 29.7 b$ & $1167.8 \pm 44.4 \mathrm{a}$ \\
\hline & Faba bean & $777.2 \pm 25.7 \mathrm{~b}$ & $1190.2 \pm 15.1 \mathrm{a}$ & $1181.0 \pm 67.5 a$ & $1167.8 \pm 44.4 \mathrm{a}$ \\
\hline & Rapeseed & $283.6 \pm 17.4 \mathrm{c}$ & $307.4 \pm 25.7 \mathrm{c}$ & $597.8 \pm 58.2 b$ & $1167.8 \pm 44.4 \mathrm{a}$ \\
\hline \multirow{3}{*}{ Spike biomass (g) } & Wheat & $1.28 \pm 0.02 \mathrm{~d}$ & $1.83 \pm 0.03 c$ & $2.08 \pm 0.04 b$ & $2.57 \pm 0.03 a$ \\
\hline & Faba bean & $2.07 \pm 0.04 c$ & $2.76 \pm 0.06 a$ & $2.73 \pm 0.03 a$ & $2.57 \pm 0.03 b$ \\
\hline & Rapeseed & $0.79 \pm 0.02 c$ & $1.01 \pm 0.04 \mathrm{c}$ & $1.41 \pm 0.04 b$ & $2.57 \pm 0.03 a$ \\
\hline \multirow{3}{*}{$\begin{array}{c}\text { Seed biomass } \\
\text { (1000-grain weight/g) }\end{array}$} & Wheat & $1.44 \pm 0.01 b$ & $1.47 \pm 0.02 b$ & $1.49 \pm 0.02 \mathrm{a}$ & $1.52 \pm 0.02 \mathrm{a}$ \\
\hline & Faba bean & $1.50 \pm 0.01 \mathrm{a}$ & $1.53 \pm 0.02 \mathrm{a}$ & $1.52 \pm 0.03 a$ & $1.52 \pm 0.02 \mathrm{a}$ \\
\hline & Rapeseed & $1.36 \pm 0.03 b$ & $1.38 \pm 0.04 b$ & $1.41 \pm 0.03 b$ & $1.52 \pm 0.02 \mathrm{a}$ \\
\hline \multirow{3}{*}{$\begin{array}{l}\text { Reproductive } \\
\text { allocation }\left(\mathrm{g} \mathrm{g}^{-1}\right)\end{array}$} & Wheat & $0.27 \pm 0.01 c$ & $0.32 \pm 0.01 b$ & $0.34 \pm 0.01 b$ & $0.40 \pm 0.01 a$ \\
\hline & Faba bean & $0.34 \pm 0.00 \mathrm{~b}$ & $0.40 \pm 0.01 a$ & $0.40 \pm 0.01 a$ & $0.40 \pm 0.01 \mathrm{a}$ \\
\hline & Rapeseed & $0.25 \pm 0.01 \mathrm{~b}$ & $0.25 \pm 0.01 b$ & $0.26 \pm 0.01 \mathrm{~b}$ & $0.40 \pm 0.01 \mathrm{a}$ \\
\hline \multirow{3}{*}{$\begin{array}{c}\text { Reproductive } \\
\text { investment }\left(\mathrm{g} \mathrm{g}^{-1}\right)\end{array}$} & Wheat & $0.17 \pm 0.01 d$ & $0.21 \pm 0.01 c$ & $0.24 \pm 0.01 b$ & $0.27 \pm 0.01 \mathrm{a}$ \\
\hline & Faba bean & $0.19 \pm 0.01 b$ & $0.27 \pm 0.01 a$ & $0.26 \pm 0.02 a$ & $0.27 \pm 0.01 \mathrm{a}$ \\
\hline & Rapeseed & $0.12 \pm 0.01 \mathrm{c}$ & $0.11 \pm 0.01 c$ & $0.16 \pm 0.02 b$ & $0.27 \pm 0.01 \mathrm{a}$ \\
\hline \multirow{3}{*}{$\begin{array}{l}\text { Reproductive index } \\
\qquad\left(\mathrm{g} \mathrm{g}^{-1}\right)\end{array}$} & Wheat & $0.62 \pm 0.03 a$ & $0.65 \pm 0.02 a$ & $0.71 \pm 0.04 a$ & $0.69 \pm 0.03 a$ \\
\hline & Faba bean & $0.56 \pm 0.03 b$ & $0.66 \pm 0.01 a$ & $0.66 \pm 0.04 a$ & $0.69 \pm 0.03 a$ \\
\hline & Rapeseed & $0.49 \pm 0.03 b$ & $0.43 \pm 0.04 b$ & $0.59 \pm 0.05 a$ & $0.69 \pm 0.03 a$ \\
\hline
\end{tabular}

Data are expressed as mean \pm standard error. The different letters within the same row mean significant differences at $p<0.05$.

\subsection{Effects of Crop Types and Tillage Methods on Physiological Traits of P. minor in Reproductive Stages}

Leaf area (LA), specific leaf area (SLA) and specific leaf weight (SLW) of P. minor were significantly affected by crop type and relative abundance in mixed culture (Table 4). In mixed culture, LA and SLW of $P$. minor were significantly $(p<0.05)$ suppressed with decreasing proportions of wheat and rapeseed, but the SLA of $P$. minor in mixed culture was greater than that in monoculture. The LA and SLW of P. minor in mixed tended to be highest in association with faba bean. The leaf area and specific leaf 
weight of $P$. minor were lowest in association with rapeseed, but SLA highest for $P$. minor in association with rapeseed.

Table 4. Leaf morphology and physiological traits of $P$. minor growing as in monoculture and in mixed culture in the reproductive stage measured $120 \mathrm{~d}$ after planting.

\begin{tabular}{|c|c|c|c|c|c|}
\hline \multirow{2}{*}{ Variables } & & \multicolumn{4}{|c|}{ Ratios (Crops: P. minor) } \\
\hline & & $2: 1$ & 1:1 & 1:2 & $0: 3$ \\
\hline \multirow{3}{*}{ Leaf area $\left(\mathrm{cm}^{2}\right)$} & Wheat & $7.0 \pm 0.2 \mathrm{c}$ & $7.3 \pm 0.3 c$ & $8.4 \pm 0.4 b$ & $9.3 \pm 0.2 a$ \\
\hline & Faba bean & $9.2 \pm 0.1 \mathrm{a}$ & $9.4 \pm 0.3 a$ & $9.3 \pm 0.3 a$ & $9.3 \pm 0.1 \mathrm{a}$ \\
\hline & Rapeseed & $4.9 \pm 0.2 d$ & $6.7 \pm 0.2 \mathrm{c}$ & $7.7 \pm 0.2 b$ & $9.3 \pm 0.1 \mathrm{a}$ \\
\hline \multirow{3}{*}{$\begin{array}{l}\text { Specific leaf area (SLA) } \\
\qquad\left(\mathrm{cm}^{2} \mathrm{~g}^{-1}\right)\end{array}$} & Wheat & $344.3 \pm 8.5 \mathrm{a}$ & $332.1 \pm 13.7 a$ & $298.9 \pm 7.6 b$ & $291.1 \pm 3.8 b$ \\
\hline & Faba bean & $315.5 \pm 3.5 \mathrm{a}$ & $283.1 \pm 4.9 \mathrm{~b}$ & $294.2 \pm 11.9 b$ & $291.1 \pm 3.8 b$ \\
\hline & Rapeseed & $370.4 \pm 12.1 \mathrm{a}$ & $344.8 \pm 10.8 b$ & $322.6 \pm 9.1 c$ & 291. $\pm 3.8 \mathrm{~d}$ \\
\hline \multirow{3}{*}{$\begin{array}{l}\text { Specific leaf weight (SLW) } \\
\qquad\left(\mathrm{mg}^{1} \mathrm{~cm}^{-2}\right)\end{array}$} & Wheat & $3.2 \pm 0.1 \mathrm{c}$ & $3.4 \pm 0.1 b c$ & $3.7 \pm 0.2 b$ & $4.2 \pm 0.1 \mathrm{a}$ \\
\hline & Faba bean & $4.4 \pm 0.1 b$ & $5.2 \pm 0.2 \mathrm{a}$ & $5.4 \pm 0.2$ & $4.2 \pm 0.1 b$ \\
\hline & Rapeseed & $2.7 \pm 0.1 \mathrm{c}$ & $2.9 \pm 0.1 \mathrm{c}$ & $3.1 \pm 0.1 b$ & $4.2 \pm 0.1 \mathrm{a}$ \\
\hline \multirow{3}{*}{$\begin{array}{l}\text { Net photosynthetic rate (Pn) } \\
\quad\left(\text { umol } \mathrm{CO}_{2} \mathrm{~m}^{-2} \mathrm{~s}^{-1}\right)\end{array}$} & Wheat & $15.1 \pm 0.3 c$ & $16.1 \pm 0.3 b$ & $16.5 \pm 0.2 b$ & $18.7 \pm 0.4 \mathrm{a}$ \\
\hline & Faba bean & $17.9 \pm 0.2 b$ & $18.1 \pm 0.1 b$ & $18.8 \pm 0.2 \mathrm{a}$ & $18.7 \pm 0.4 \mathrm{ab}$ \\
\hline & Rapeseed & $14.4 \pm 0.3 c$ & $14.8 \pm 0.2 \mathrm{c}$ & $15.7 \pm 0.2 b$ & $18.7 \pm 0.4 \mathrm{a}$ \\
\hline \multirow{3}{*}{$\begin{array}{l}\text { Stomatal conductance, (Gs) } \\
\qquad\left(\mathrm{mol} \mathrm{H}_{2} \mathrm{O} \mathrm{m}^{-2} \mathrm{~s}^{-1}\right)\end{array}$} & Wheat & $0.32 \pm 0.01 b$ & $0.34 \pm 0.02 \mathrm{ab}$ & $0.35 \pm 0.01 \mathrm{ab}$ & $0.37 \pm 0.01 \mathrm{a}$ \\
\hline & Faba bean & $0.34 \pm 0.01 \mathrm{a}$ & $0.36 \pm 0.01 \mathrm{a}$ & $0.37 \pm 0.02 \mathrm{a}$ & $0.37 \pm 0.01 \mathrm{a}$ \\
\hline & Rapeseed & $0.29 \pm 0.01 c$ & $0.29 \pm 0.02 c$ & $0.33 \pm 0.01 b$ & $0.37 \pm 0.01 \mathrm{a}$ \\
\hline \multirow{3}{*}{$\begin{array}{l}\text { Intercellular } \mathrm{CO}_{2} \\
\text { conductance }(\mathrm{Ci}) \\
\quad\left(\text { umol mol }{ }^{-1}\right)\end{array}$} & Wheat & $294.3 \pm 4.3 a$ & $291.6 \pm 2.8 \mathrm{ab}$ & $288.4 \pm 2.7 \mathrm{ab}$ & $283.5 \pm 2.2 b$ \\
\hline & Faba bean & $286.0 \pm 2.4 a$ & $284.2 \pm 3.8 \mathrm{a}$ & $280.4 \pm 39.4 a$ & $283.5 \pm 2.2 \mathrm{a}$ \\
\hline & Rapeseed & $289.3 \pm 3.7 a$ & $288.5 \pm 3.7 a$ & $292.3 \pm 1.7 \mathrm{a}$ & $283.5 \pm 2.2 \mathrm{a}$ \\
\hline \multirow{3}{*}{$\begin{array}{l}\text { Transpiration rate }(\mathrm{Tr}) \\
\left(\mathrm{mmol} \mathrm{H}_{2} \mathrm{O} \mathrm{m}^{-2} \mathrm{~s}^{-1}\right)\end{array}$} & Wheat & $4.0 \pm 0.0 c$ & $4.2 \pm 0.1 b c$ & $4.3 \pm 0.0 b$ & $4.9 \pm 0.1 \mathrm{a}$ \\
\hline & Faba bean & $4.7 \pm 0.1 b$ & $4.9 \pm 0.1 \mathrm{ab}$ & $5.0 \pm 0.1 \mathrm{a}$ & $4.9 \pm 0.1 \mathrm{ab}$ \\
\hline & Rapeseed & $3.9 \pm 0.1 c$ & $3.8 \pm 0.1 c$ & $4.2 \pm 0.1 b$ & $4.9 \pm 0.1 \mathrm{a}$ \\
\hline \multirow{3}{*}{$\begin{array}{l}\text { Water use efficiency (WUE) } \\
\text { (umol } \mathrm{CO}_{2} \mathrm{mmol} \mathrm{H}_{2} \mathrm{O}^{-1} \text { ) }\end{array}$} & Wheat & $3.8 \pm 0.1 \mathrm{a}$ & $3.9 \pm 0.1 \mathrm{a}$ & $3.9 \pm 0.1 \mathrm{a}$ & $3.8 \pm 0.1 \mathrm{a}$ \\
\hline & Faba bean & $3.8 \pm 0.1 \mathrm{a}$ & $3.74 \pm 0.1 \mathrm{a}$ & $3.7 \pm 0.1 \mathrm{a}$ & $3.8 \pm 0.1 \mathrm{a}$ \\
\hline & Rapeseed & $3.7 \pm 0.1 \mathrm{a}$ & $3.87 \pm 0.1 \mathrm{a}$ & $3.7 \pm 0.1 \mathrm{a}$ & $3.8 \pm 0.1 \mathrm{a}$ \\
\hline
\end{tabular}

Crop types and relative abundance also significantly influenced the physiological characteristic of P. minor (Table 4). When P. minor was grown with wheat or rapeseed, the net photosynthetic rate (Pn), stomatal conductance (Gs) and transpiration rate (Tr) decreased significantly compared to P. minor grown in monoculture (but note that Gs was only higher for monoculture compared to wheat in the 2:1 mix). However, there were no significant differences in Gs for P. minor grown with faba bean, although the Tr was largest for a 1:2 ratio crop to $P$. minor. The intercellular $\mathrm{CO}_{2}$ concentration $\left(\mathrm{C}_{\mathrm{I}}\right)$ varied little for $P$. minor in mixed culture with faba bean and rapeseed, but at a 2:1 ratio of wheat to $P$. minor $\mathrm{C}_{\mathrm{i}}$ was significantly higher than in monoculture. There were no significant differences in water use efficiency (WUE) between mixed culture and monoculture. To sum up the results: the Pn, Gs and $\operatorname{Tr}$ of P. minor in association with faba bean and wheat were the greatest, while the Pn, Gs and Tr for P. minor in association with rapeseed were the smallest.

\section{Discussion}

Control of invasive weeds utilizing cropping systems is an important current research topic $[13,30,31]$, but specific information on managing P. minor via such an approach is limited. For annual weeds like P. minor, understanding the seed dormancy, germination reproductive characteristics under different cropping systems is critical for designing appropriate systems that provide ecological advantages allowing pesticide use to be reduced [32-34]. Among the cropping systems tested in our dormancy experiments, we found crop types significantly affected the seed 
dormancy of this weed, as seeds can remain dormant for a long time in paddy fields (less than $10 \%$ germination by the 150th day). In our seed germination experiment, we found that increasing soil depth significantly decreased the germination rate and germination index of P. minor. Our field experiment showed rapeseed significantly reduced the total biomass, spike biomass, spike number and seed number of $P$. minor. Together, these results suggested that cropping systems could be designed to regulate seed dormancy, inhibit seed germination and reduced the soil seed banks of $P$. minor.

Weed seed dormancy is a critical issue for weed control and varies greatly under different environmental conditions [13]. Previous studies found that seed dormancy of $P$. minor could be broken via specific conditions involving sunlight, temperature, or soil moisture $[15,18]$. Our research showed that seed dormancy of $P$. minor was affected by different cropping systems, as $P$. minor exhibited higher germination rates in maize fields and bare, dry soil and exhibited extremely low germination rates in submerged paddy fields $(<10 \%)$. The main crops grown in Yunnan during the dormancy period of P. minor are rice and maize. Our results suggested that before sowing winter crops, if the previous crop was maize or fallow, the control of this weed could be timed to coincide with $P$. minor emergence. However, if the previous crop was rice, the water level could be kept elevated as long as possible before sowing winter crops, so as to delay the emergence of this weed, and put it at a disadvantage. Thus, strategically rotating other systems such as paddy rice with rapeseed could reduce P. minor germination and help deplete its seed bank.

Weed seed germination may be greatly affected by soil microclimate conditions, such as temperature and soil moisture, as influenced by crop type. Some studies found that some crops, such as pearl millet, black gram, green gram, sorghum, soybean and sunflower could delay and inhibit seed germination of P. minor [32-34]. However, our study showed three crops (wheat, faba bean and rapeseed) had no effect on the seed germination percentage of $P$. minor, but that its germination time was delayed significantly by rapeseed. Some crops are confirmed to have inhibitory effects on the germination of P. minor and can be further explored as natural alternatives to chemical herbicides $[35,36]$. Our previous research showed that rapeseed had strong competitive ability against $P$. minor while the current research suggests that rapeseed may gain a competitive advantage over $P$. minor by delaying its germination [23]. In addition, we did also show that increasing soil burial depth significantly reduced seed germination of P. minor implying that agricultural measures such as deep-tillage could reduce P. minor populations.

Our research also showed that rapeseed could significantly reduce the spike biomass, spike number and seed number of $P$. minor, while low-density faba bean could actually promote these growth characteristics. Previous studies showed that $P$. minor had high reproductive capacity and robust ecological adaptability [5]. We have previously studied the competitive effects between native crops (wheat, faba bean and rapeseed) and P. minor, and these studies showed that rapeseed was the strongest while faba bean was the weakest under the same conditions [23]. Therefore, utilizing interspecific competition the seed number of $P$. minor may be reduced by planting highly competitive species, thus overcoming the inherent adaptability of this invasive species, as normally realized via high levels of fecundity. Moreover, our research also showed the reproductive allocation, reproductive investment and reproductive index of $P$. minor in rapeseed fields were the lowest while $P$. minor exhibited the highest reproductive potential in association with faba bean. Many invasive alien species have strong ecological adaptability, allowing them to allocate resources strategically to manage the inevitable trade-off between growth and reproduction [37].

Functioning leaf area can reflect a plant's strategy for maximizing the capture and utilization of environmental resources [38]. Thus, leaf area is generally useful in assessing the growth condition and solar energy utilization efficiency of plants [39]. Greater specific leaf area (leaf area per unit leaf mass) may increase carbon assimilation due to more leaf area produced for a given investment in biomass [40]. Our study showed that in all mixed culture treatments, the leaf area and specific leaf weight of $P$. minor were lowest in rapeseed fields and highest in faba bean fields, indicating that rapeseed was the most competitive crop. Higher rates of photosynthesis connected to higher leaf areas 
can lead to increased growth rates, biomass accumulation and overall production. Higher carbon gain and growth may enable many invasive species to readily outcompete slower-growing species by facilitating colonization or resource acquisition [40]. The net photosynthetic rate, stomatal conductance and transpiration rate of $P$. minor also decreased significantly while grown with wheat or rapeseed. We found the Pn of P. minor was significantly higher in monoculture than in mixed culture with rapeseed and wheat, demonstrating that interspecific competition reduced its rate of photosynthesis. Thus, it is clear that impacts of rapeseed on the structural and physiological traits of $P$. minor were generally more pronounced than for wheat and faba bean, suggesting that growing rapeseed crops may be more effective at inhibiting $P$. minor than wheat or faba bean.

Our results also have significant implications for ecological control theory and more general applications to management of invasive weeds in agro-ecosystems. Ecological control of weeds in farmland is still a worldwide challenge because of human demand for food and high economic returns. Some invasive weeds have highly persistent soil seed banks in invaded habitats. Our research showed that cropping system could affect the seed dormancy of invasive weeds, and the design of cropping system could regulate the temporal and spatial distribution of invasive weed populations, which is conducive to the ecological control of weeds. In addition, our research also showed that planting strong competitive crops could reduce the harmfulness of invasive weeds and minimize the use of herbicides. Some researchers also argue that certain cropping systems may be more successful than others in resisting invasion and provide ecological control [41]. Compared to manual uprooting and chemical control, ecological control clearly has the potential to provide a more sustainable management option for growers, as shown in the present study and other related studies [42,43]. Our research revealed that rapeseed can significantly restrain growth, reduce seed number and increase germination time of P. minor. In view of our findings on the impact of microsite conditions on the germination and growth of $P$. minor, ecological control measures should be designed to involve both appropriate crop rotations and tillage management, in order to manage the ecosystem effectively.

\section{Conclusions}

This study demonstrated the roles of selected crop types and seed and seedling microclimate conditions in potentially regulating seed dormancy, inhibiting seed germination and the reproductive ability of $P$. minor, thus reducing establishment and spread of $P$. minor populations. Our findings suggest optimal cropping systems design could involve planting rapeseed in conjunction with deep plowing and planting rice (continuous submergence underwater) in summer. Such a system could reduce the field populations and seed bank of P. minor, thus providing a sustainable and environmentally friendly means of suppressing P. minor.

Author Contributions: L.D. and F.Z. conceived and designed the experiments; G.X., S.S., S.Y., Y.Z., G.J. and Y.G. performed the experiments; G.X., D.R.C. and J.L. analyzed the data and wrote drafts; S.S. and D.R.C. edited the manuscript for style; L.D. and F.Z. commented on manuscript. All authors read and approved the final manuscript.

Funding: This research was supported by the Applied Basic Research Foundation of Yunnan Province (2017FB055), the Middle-aged and Young Academic Leader training foundation of Yunnan Province (2018HB054), the Ten Thousand Talent Program (Young Top-notch Talent) of Yunnan Province (2019-2023), the Applied Basic Research Foundation of Yunnan Province (2017FB049), the State Scholarship Fund of China Scholarship Council (201808530029), the Program for the Innovative Research Team of Yunnan Province (2020-2022) and the Key Research and Development Program of Yunnan Province (2019IB007).

Acknowledgments: We wish to thank Yuhua Zhang from the Agricultural Environment and Resource Research Institute, Yunnan Academy of Agricultural Sciences for her great field support.

Conflicts of Interest: The authors declare no conflict of interest. The founding sponsors had no role in the design of the study; in the collection, analyses, or interpretation of data; in the writing of the manuscript and in the decision to publish the results. 


\section{References}

1. Gonzalez-Andujar, J.L.; Saavedra, M. Spatial distribution of annual grass weed populations in winter cereals. Crop Prot. 2003, 22, 629-633. [CrossRef]

2. Singh, S.; Kirkwood, R.C.; Marshall, G. Biology and control of Phalaris minor Retz. (littleseed canarygrass) in wheat. Crop Prot. 1999, 18, 1-16. [CrossRef]

3. Rajender, S.C.; Ramesh, K.S. Multiple herbicide resistance in littleseed canarygrass (Phalaris minor): A threat to wheat production in India. Weed Biol. Manag. 2008, 8, 112-123. [CrossRef]

4. Chhokar, R.S.; Sharma, R.K.; Chauhan, D.S.; Mongia, A.D. Evaluation of herbicides against Phalaris minor in wheat in north-western Indian plains. Weed Res. 2006, 46, 40-49. [CrossRef]

5. Xu, G.; Zhang, F.; Li, T.; Shan, Q.; Zhang, Y.; Wu, D. Biological characteristics, influence on growth of wheat and its economical threshold of Phalaris paradoxa L. and Phalaris minor Retz. Sci. Agric. Sin. 2010, 43, $4409-4417$.

6. Khawar, J.; Muhammad, F.; Mubshir, H.; Hafeez ur, R.; Muhammad, A.A. Wild oat (Avena fatua L.) and canary grass (Phalaris minor Ritz.) management through allelopathy. J. Plant Prot. Res. 2010, 50, 41-44.

7. Tang, D.; Yang, X.; Li, Y.; Xiao, W.; Gu, X.; Jing, D.; Li, R.; Fu, Y. Investigation on the occurrence, damage and control of the invasive weed Phalaris spp. in Yunnan Province. Plant Prot. 2018, 44, 167-169.

8. Travlos, I.S.; Chachalis, D. Glyphosate-resistant hairy fleabane (Conyza bonariensis) is reported in Greece. Weed Technol. 2010, 24, 569-573. [CrossRef]

9. Chhokar, R.S.; Malik, R.K. Isoproturon-resistant littleseed canarygrass (Phalaris minor) and its response to alternate herbicides. Weed Technol. 2002, 16, 116-123. [CrossRef]

10. Afentouli, C.G.; Eleftherohorinos, I.G. Competition between wheat and canarygrass biotypes and their response to herbicides. Weed Sci. 1999, 47, 55-61. [CrossRef]

11. Amini, R. Allelopathic potential of littleseed canary grass (Phalaris minor Retz.) on seedling growth of barley (Hordeum vulgare L.). J. Biodivers. Environ. Sci. 2013, 3, 85-91.

12. Om, H.; Kumar, S.; Dhiman, S.D. Biology and management of Phalaris minor in rice-wheat system. Crop Prot. 2004, 23, 1157-1168. [CrossRef]

13. Richardson, D.M.; Pyšek, P. Plant invasions: Merging the concepts of species invasiveness and community invasibility. Prog. Phys. Geogr. 2006, 30, 409-431. [CrossRef]

14. Rilov, G.; Schiel, D.R. Seascape-dependent subtidal-intertidal trophic linkages. Ecology 2006, 87, 731-744. [CrossRef] [PubMed]

15. Conn, J.S. Effects of tillage and cropping sequence on Alaskan weed vegetation: Studies on land under cultivation for eleven years. Soil Tillage Res. 1987, 9, 265-274. [CrossRef]

16. Chauhan, B.S.; Singh, R.G.; Mahajan, G. Ecology and management of weeds under conservation agriculture: A review. Crop Prot. 2012, 38, 57-65. [CrossRef]

17. Om, H.; Dhiman, S.D.; Hemant, K.; Sajjan, K. Biology and management of Phalaris minor in wheat under a rice/wheat system. Weed Res. 2003, 43, 59-67. [CrossRef]

18. Om, H.; Kumar, S.; Dhiman, S.D. Dormancy and viability of Phalaris minor seed in a rice-wheat cropping system. Weed Res. 2005, 45, 140-148. [CrossRef]

19. Singh, V.; Singh, H.; Raghubanshi, A.S. Competitive interactions of wheat with Phalaris minor or Rumex dentatus: A replacement series study. Int. J. Pest Manag. 2013, 59, 245-258. [CrossRef]

20. Mahajan, G.; Brar, L.S. Integrated management of Phalaris minor in wheat: Rationale and approaches-A review. Agric. Rev. 2002, 23, 241-251.

21. Shen, S.; Zhang, F.; Xu, G.; Li, T.; Wu, D.; Zhang, Y. Occurrence and infestation of invasive weed in crop field in Yunnan. Southwest China J. Agric. Sci. 2012, 25, 554-561.

22. Xu, G.; Zhang, F.; Li, T.; Shen, S.; Zhang, Y. Influence of environmental factors on seed germination of Phalaris paradoxa and Phalaris minor. Acta Bot. Boreali-Occident. Sin. 2011, 31, 1458-1465.

23. Xu, G.; Zhang, Y.; Shen, S.; Zhang, F.; Li, T.; Jin, G. Effect of crop species and mixed ratios on morphological plasticity and competitiveness of Phalaris minor Retz. Chin. J. Eco-Agric. 2013, 21, 1507-1514. [CrossRef]

24. Shen, S.; Xu, G.; Li, D.; Jin, G.; Liu, S.; Clements, D.R.; Yang, Y.; Rao, J.; Chen, A.; Zhang, F.; et al. Ipomoea batatas (sweet potato), a promising replacement control crop for the invasive alien plant Ageratina adenophora (Asteraceae) in China. Manag. Biol. Invasions 2019, 10, 559-572. [CrossRef]

25. Obeso, J.R. The costs of reproduction in plants. New Phytol. 2002, 155, 321-348. [CrossRef] 
26. Poorter, L. Growth responses of 15 rain-forest tree species to a light gradient: The relative importance of morphological and physiological traits. Funct. Ecol. 1999, 13, 396-410. [CrossRef]

27. De Wit, C.T. On competition. Versl. Landbouwk. Onderzoek. 1960, 66, 1-82.

28. Field, C.; Mooney, H.A. The Photosynthesis-Nitrogen Relationship in Wild Plants on the Economy of Plant Form and Function; Givnish, T.J., Ed.; Cambridge University Press: Cambridge, UK, 1986; pp. 25-55.

29. Pearcy, R.W.; Ehleringer, J.R.; Mooney, H.A.; Rundel, P.W. Plant Physiological Ecology: Field Methods and Instrumentation; Chapman \& Hall: London, UK, 1989.

30. Shen, S.C.; Xu, G.F.; Clements, D.R.; Jin, G.M.; Chen, A.D.; Zhang, F.D.; Hisashi, K.N. Suppression of the invasive plant mile-a-minute (Mikania micrantha) by local crop sweet potato (Ipomoea batatas) by means of higher growth rate and competition for soil nutrients. BMC Ecol. 2015, 15, 1. [CrossRef]

31. Shen, S.; Xu, G.; Li, D.; Jin, G.; Liu, S.; Clements, D.R.; Yang, Y.; Rao, J.; Chen, A.; Zhang, F.; et al. Potential use of sweet potato (Ipomoea batatas (L.) Lam.) to suppress three invasive plant species in agroecosystems (Ageratum conyzoides L., Bidens pilosa L., and Galinsoga parviflora Cav.). Agronomy 2019, 9, 318. [CrossRef]

32. De Casas, R.R.; Kovach, K.; Dittmar, E.; Barua, D.; Barco, B.; Donohue, K. Seed after-ripening and dormancy determine adult life history independently of germination timing. New Phytol. 2012, 194, 868-879. [CrossRef]

33. Chachalis, D.; Reddy, K.N. Factors affecting Campsis radicans seed germination and seedling emergence. Weed Sci. 2000, 48, 212-216. [CrossRef]

34. Grundy, A.C.; Phelps, K.; Reader, R.J.; Burston, S. Modelling the germination of Stellaria media using the concept of hydrothermal time. New Phytol. 2000, 148, 433-444. [CrossRef]

35. Abbas, T.; Nadeem, M.A.; Tanveer, A.; Ali, H.H.; Safdar, M.; Zohaib, A.; Farooq, N. Exploring the herbicidal and mormetic potential of allelopathic crops against fenoxaprop-resistant Phalaris minor. Planta Daninha 2018, 36, e018176368. [CrossRef]

36. El-Darier, S.M.; El-Kenany, E.T.; Abdellatif, A.A.; Hady, E.N.F.A. Allelopathic prospective of Retama raetam L. against the noxious weed Phalaris minor Retz. growing in Triticum aestivum L. fields. Rend. Lincei-Sci. Fis. 2018, 29, 155-163. [CrossRef]

37. Simberloff, D.; Martin, J.L.; Genovesi, P.; Maris, V.; Wardle, D.A.; Aronson, J.; Courchamp, F.; Galil, B.; García-Berthou, E.; Pascal, M.; et al. Impacts of biological invasions: What's what and the way forward. Trends Ecol. Evol. 2013, 28, 58-66. [CrossRef] [PubMed]

38. Baldwin, I.T.; Schmelz, E.A. Constraints on an induced defense: The role of leaf area. Oecologia 1994, 97, 424-430. [CrossRef]

39. Quero, J.L.; Villar, R.; Marañón, T.; Zamora, R. Interactions of drought and shade effects on seedlings of four Quercus species: Physiological and structural leaf responses. New Phytol. 2006, 170, 819-834. [CrossRef]

40. Lambers, H.; Poorter, H. Inherent variation in growth rate between higher plants: A search for physiological causes and ecological consequences. Adv. Ecol. Res. 1992, 23, 187-261. [CrossRef]

41. Gaba, S.; Fried, G.; Kazakou, E.; Chauvel, B.; Navas, M.L. Agroecological weed control using a functional approach: A review of cropping systems diversity. Agron. Sustain. Dev. 2014, 34, 103-119. [CrossRef]

42. Vivek; Naresh, R.K.; Tomar, S.K.; Kumar, S.; Mahajan, N.C.; Shivani. Weed and water management strategies on the adaptive capacity of rice-wheat system to alleviate weed and moisture stresses in conservation agriculture: A review. Int. J. Chem. Stud. 2019, 7, 1319-1334.

43. Malik, R.K.; Kumar, V.; McDonald, A. Conservation agriculture-based resource-conserving practices and weed management in the rice-wheat cropping systems of the Indo-Gangetic Plains. Indian J. Weed Sci. 2018, 50, 218-222. [CrossRef]

(C) 2019 by the authors. Licensee MDPI, Basel, Switzerland. This article is an open access article distributed under the terms and conditions of the Creative Commons Attribution (CC BY) license (http://creativecommons.org/licenses/by/4.0/). 